- Almost half of the practitioners surveyed were aware of the Atraumatic Restorative Treatment technique (ART).

- Few practitioners, however, followed ART principles in their practice.

- Further education on minimal intervention techniques would seem desirable.

\title{
UK dentists' attitudes and behaviour towards Atraumatic Restorative Treatment for primary teeth
}

\author{
F. J. T Burke, ${ }_{1}^{1}$ S. McHugh, ${ }_{1}^{2}$ L. Shaw, ${ }_{1}^{3}$ M-T. Hosey, ${ }_{1}^{4}$ L. Macpherson, ${ }_{1}^{5}$ S. Delargy ${ }^{6}$ and B. Dopheide ${ }^{7}$
}

\begin{abstract}
Background Atraumatic Restorative Treatment (ART) was introduced a decade ago as a minimal intervention treatment for caries in unindustrialised countries, but UK general dental practitioners (GDPs) may also be using this technique.

Objective This study aimed to determine the materials and techniques used by a group of UK GDPs to treat caries in primary teeth.

Method A questionnaire, designed to determine GDPs' use of materials and techniques in the restoration of caries in primary teeth, was distributed to 600 GDPs in Scotland and England, with an explanatory letter and reply-paid envelope. The questionnaire included colour illustrations of two carious cavities in primary molar teeth and a request that respondents draw the cavity outline that they would use on the illustrations. The cavity outlines were assessed independently by two examiners. All other data were collated and analysed.
\end{abstract}

Results 390 usable replies were received, a response rate of $65 \%$. Of the respondents, $99 \%$ treated child patients and $42 \%$ of respondents were aware of ART. For treatment of a small Class II cavity, 37\% drew a cavity outline without extension beyond removal of caries and a majority suggested use of an adhesive material (51\% glass ionomer, $13 \%$ compomer). For cavity preparation, $47 \%$ of respondents used a drill, 10\% an excavator and $41 \%$ used both. For treatment of a large occluso-lingual cavity, again most used an adhesive technique (44\% glass ionomer, $12 \%$ compomer) for its restoration, while $50 \%$ used a drill, 7\% an excavator and 42\% used both for cavity preparation. Conclusion Most respondents used adhesive materials for restoration of caries in primary molars, but, despite $42 \%$ of respondents stating that they were aware of the treatment, 'true' ART was adopted by fewer than $10 \%$ of respondents.

\footnotetext{
$1^{*}$ Professor of Primary Dental Care ${ }^{3}$ Retired Senior Lecturer/Hon Consultant in Paediatric Dentistry, University of Birmingham; ${ }^{2}$ Research Statistician, ${ }^{4}$ Clinical Senior Lecturer/Hon Consultant in Paediatric Dentistry, ${ }^{5}$ Clinical Senior Lecturer/Hon Consultant in Dental Public Health, Glasgow Dental School; ${ }^{6}$ General Dental Practitioner, Birmingham; ${ }^{7}$ Research Co-ordinator, GC Europe, Leuven, Belgium

${ }^{*}$ Correspondence to: Professor F. J. T. Burke, University of Birmingham, School of Dentistry, St Chad's Queensway, Birmingham, B4 6NN

Email:f.j.t.burke@bham.ac.uk
}

\section{Refereed paper}

Accepted 7 September 04

doi: 10.1038/sj.bdj.4812696

British Dental Journal 2005; 199: 365-369

\section{INTRODUCTION}

The management of caries in the primary dentition is an important aspect of general dental practice, but there is evidence in the UK that caries in primary teeth is not always treated by restorative intervention in most children. ${ }^{1}$ This may take the form of making cavities self-cleansing in the hope that caries will arrest if the diet can be made non-cariogenic, or it may take the form of supervised non-treatment.

The level of emotional maturity, previous dental experience, influence of the family, the dental surgery environment and the dental team may all affect how a child with dental caries is managed. Stabilisation using minimal tooth tissue removal can be used as part of a holistic approach to the management of a pre-cooperative or anxious child. ${ }^{2}$ The efficacy of restoring the primary dentition at all has been the subject of recent debate ${ }^{3,4}$ and treatment by extraction is common. ${ }^{5}$ Partial caries removal followed by placement of an adhesive restorative material may buy time by slowing progress of the disease whilst the child learns how to cope with dental treatment. ${ }^{6,7}$ As a result, general dental practitioners (GDPs) may elect to do step-wise excavation of caries and restoration of the cavity with an adhesive material rather than to administer local anaesthesia and restore the cavity with a classical Black's style Class I or II restoration in amalgam, or a stainless steel crown. However, little is known about how UK GDPs actually treat cavitated carious lesions in primary teeth, nor UK dentists' acceptance of the Atraumatic Restorative Treatment technique.

\section{Atraumatic Restorative Treatment}

An alternative approach to the management of caries was tested in Africa in the mid 1980s, ${ }^{8}$ and at the initiative of the World Health Organisation (WHO) and manufacturers of glass ionomer materials, Atraumatic Restorative Treatment (ART) was first described..$^{9}$ This involved the excavation of caries by hand instruments such as spoon excavators and the restoration of the cavity using an adhesive material, usually a reinforced glass ionomer cement. ${ }^{10}$ This allowed dentistry to be done in less industrialised areas of countries where the supply of electricity might be unreliable.

Specially designed criteria have been developed for the assessment of restorations using the ART technique, making comparison between success rates of ART restorations and those placed using conventional techniques difficult. Nevertheless, the ART approach has been found to be well received by patients who have not previ- 
ously received restorative care. ${ }^{11}$ It has also been calculated that the longevity of class I ART restorations compared favourably with longevity data in the UK on conventional amalgam restorations, ${ }^{11}$ although the criteria used in some surveys on ART might not be the same as those more often used in clinical evaluations. ${ }^{11}$ However, success rates of class II restorations placed using the ART technique might not be so favourable when compared with conventional techniques. ${ }^{12}$

\section{Aims of project}

There is anecdotal evidence from GDPs that a form of ART is being used to treat cavitated carious lesions in primary teeth in general dental practice in the UK, but information on the prescribed treatment is sparse. Although most clinical trials of ART involve single surface lesions, ART has also been suggested as an appropriate technique for some multi-surface cavities. ${ }^{9}$ The aim of this study was therefore to provide a preliminary understanding of the treatment modalities prescribed by a group of UK GDPs in the treatment of multi-surface carious cavities in primary teeth.

\section{MATERIALS AND METHODS}

A questionnaire was designed to determine the techniques and materials prescribed for treatment of caries in primary teeth. Most of the questions were on demographic details of the respondents and the techniques and materials which they used in treatment of caries in the primary dentition. Respondents were also asked to draw their preferred cavity outline on colour illustrations of two cavities that were considered representative of carious lesions which would be treated by GDPs and with which patient details were provided, as follows:

Figure 1a shows a class II carious cavity in a primary mandibular first molar tooth. The questionnaire presented the scenario that this was a cooperative seven-year-old child in whose tooth the enamel had been undermined by approximately $1 \mathrm{~mm}$ by caries, and that the child had two other carious teeth.

- Figure $1 \mathrm{~b}$ shows a large occluso-lingual carious cavity in a primary mandibular second molar tooth. The questionnaire presented the scenario that this was a cooperative seven-yearold child in whose tooth the enamel has been undermined by
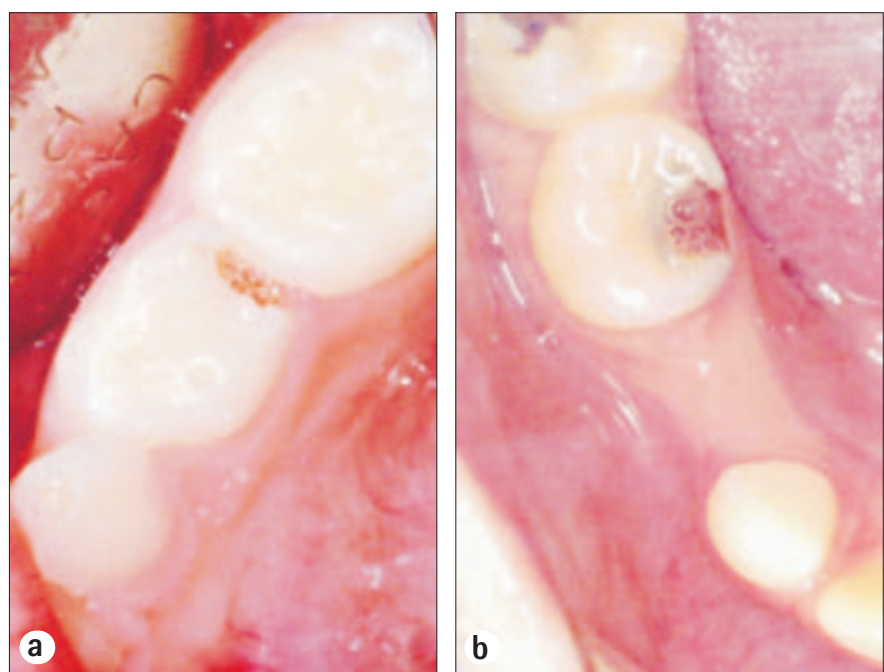

Figs $1 \mathrm{a}$ and $1 \mathrm{~b}$ Illustrations of cavities which were printed on to the questionnaire

approximately $1.5 \mathrm{~mm}$ of caries, and that the child had two other carious teeth.

The questionnaire was piloted among a group of ten GDPs who hold part-time teaching posts at the University of Birming- ham's School of Dentistry. Following minor amendments, as suggested by these GDPs, the questionnaire was distributed in Spring 2002 to 300 GDPs in the West Midlands, England and 300 across Scotland, whose names were randomly selected from Health Authority and Health Board lists of GDPs. The questionnaire was accompanied by a reply-paid envelope and a letter that said that no second mailing would be sent, due to budgetary constraints, and requested completion and return of the questionnaire within one month. The design of the questionnaire and the accompanying letter were in accordance with the Total Design Method suggested by Dillman. ${ }^{13}$

The data in the returned questionnaires were entered into a Microsoft Access database and analysed using Minitab (version 12). Statistical analyses involved descriptive statistics and cross-tabulations, with potential associations tested for statistical significance using Chi-square tests (or Fisher's Exact test when small numbers dictated) and appropriate follow-up multiple comparisons as necessary.

Cavity designs and treatments proposed by respondents for the class II cavity in Fig. 1a were classified into four groups, as follows:

Treatment 1: Cavity outline closely following the outline of the carious cavity, or some slight additional preparation beyond the caries

Treatment 2: Conservative Black's Class II design

Treatment 3: Non-conservative Black's Class II design

Treatment 4: Other.

Treatments proposed by respondents for the cavity in Fig. $1 \mathrm{~b}$ were classified into three groups, as follows:

Treatment 1: Cavity outline closely following the outline of the carious cavity, some slight additional preparation beyond the caries

Treatment 2: Non-conservative design with additional retentive features

Treatment 3: Other

A 'no treatment' category was available for both cavities.

A general dental practitioner and an academic with experience in treating caries in primary teeth independently assessed the cavity outlines suggested by the respondents and classified them into the above groups. A third dentist arbitrated in cases where the two assessors could not reach agreement.
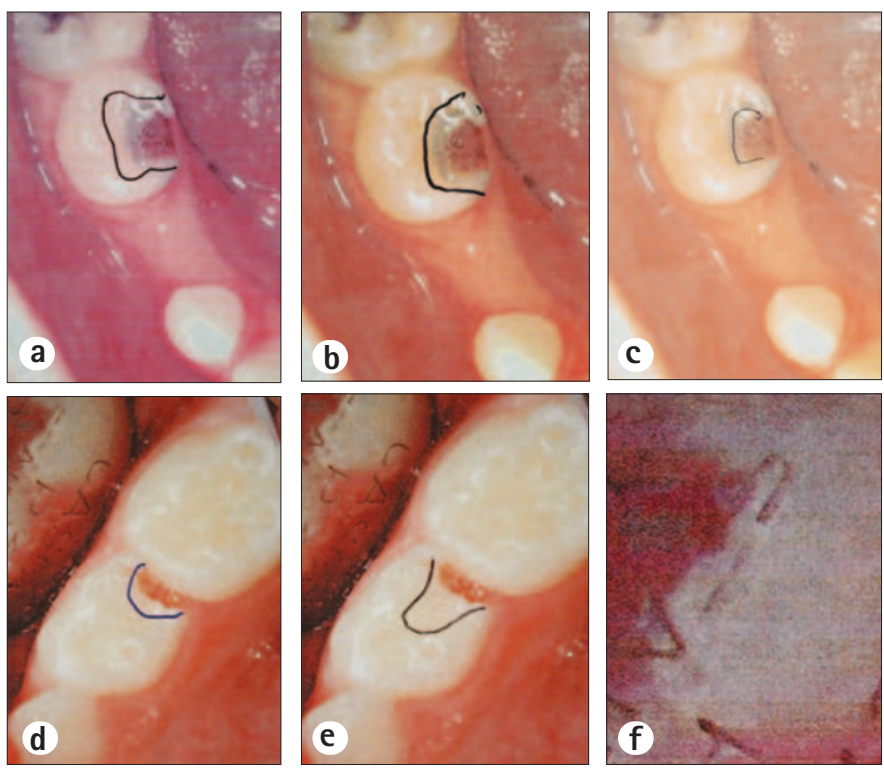

Fig. 2 A selection of cavity designs suggested by respondents:

Cavities were assigned the following treatment codes by the assessors as follows: $2 \mathrm{a}$ - code $2 ; 2 \mathrm{~b}$ - code $1 ; 2 \mathrm{c}$ - code $1 ; 2 \mathrm{~d}$ - code $1 ; 2 \mathrm{e}-$ code 3 ; $2 \mathrm{f}$-code 3 


\section{RESULTS}

Data are presented in percentages, together with an indication of the number of responses per question, due to fluctuations in the number of responses, as all of the questions were not answered by all of the respondents.

\section{General and demographic data}

Replies were received from 390 dentists, a response rate of 65\%. Sixty-nine per cent $(261 / 380)$ of the respondents were male. Regarding years since graduation, 14\% (52/381) had graduated between one and five years ago, 14\% $(n=53)$ between 6 and 10 years, 33\% $(n=125)$ between 11 and 20 years and 39\% $(n=151)$ had graduated 21 years ago or more.

Eighteen per cent (67/381) practised single-handed. Fifty-four per cent (204/379) of practices were in a city or town centre, 44\% $(n=166)$ were in a suburban location and $2 \%(n=9)$ in a rural location. When asked to state the number of years in their present practice, the mean number was 12 years (SD: 9), the median was 11 years and the range 0 to 33 years. Thirty-nine per cent of respondents (148/378) practised in an area where the water was fluoridated.

Ninety-nine per cent (374/378) of respondents treated child patients in their practice, the mean percentage of patients in the respondents' practices who were less than 18 years being 25\% (SD: 16: median 20\% and range 0-99\%).

Fifty-four per cent (193/358) of respondents stated that they would consider employing a dental therapist to treat children.

Forty-two per cent of respondents (154/371) said they were aware of ART. There was evidence of a significant association between school and awareness of ART, with a significantly smaller percentage of respondents from Glasgow being aware of ART (30\%: 34/112) compared with graduates from 'other schools' (55\%: 39/71).

Treatments suggested for the cavity are illustrated in Figure 1a Treatments proposed by respondents for this cavity were classified, as follows:

- Treatment 1: Cavity outline closely following the outline of the carious cavity, or some slight additional preparation beyond the caries 75\% (278/372)

- Treatment 2: Conservative Black's Class II design 7\% (26/372)

- Treatment 3: Non-conservative Black's Class II design 11\% (40/372)

- Treatment 4: Other 1\% (5/372)

- No treatment 6\% (23272).

The materials/treatments suggested are shown in Table 1. Among the comments made were: use Cermet, and, pulp medicament needed.

$\begin{aligned} & \text { Table } 1 \text { Materials/treatments suggested (359 responses) for cavity } \\
& \text { in Figure 1a }\end{aligned}$
\begin{tabular}{lcc}
\hline Nreatment & No. of responses & Percentage \\
\hline Stainless steel crown & 7 & $2 \%$ \\
Cavity made self cleansing & 7 & $2 \%$ \\
Restore with amalgam & 45 & $13 \%$ \\
Restore with glass-ionomer & 182 & $51 \%$ \\
Restore with compomer & 47 & $13 \%$ \\
Restore with amalgam/g.ionomer & 24 & $7 \%$ \\
Restore with g.ionomer/compomer & 20 & $6 \%$ \\
Restore with composite & 3 & $<1 \%$ \\
Other & 24 & $7 \%$
\end{tabular}

When asked how they would remove the caries, 10\% (35/360) of respondents indicated that they would use only an excavator, $47 \%$ $(\mathrm{n}=169)$ would use a drill, 41\% ( $\mathrm{n}=148)$ would use an excavator and drill and 2\% (n=6) would use excavator, drill and chemical. Thirty per cent (104/354) of respondents would use local anaesthesia for the treatment suggested, while $4 \%(n=14)$ would administer relative analgesia. With regard to the respondents' expectation for success of their proposed treatment, 30\% (105/352) considered that the prognosis would be excellent, 69\% $(n=243)$ fair and $1 \%(n=4)$ poor. Ninety-eight per cent of respondents (345/351) would use cotton rolls for isolation, whilst $1 \%(\mathrm{n}=3)$ would use rubber dam.

Treatments suggested for the cavity illustrated in Fig. 1b and treatments proposed by respondents for this cavity were classified as:

- Treatment 1: Cavity outline closely following the outline of the carious cavity, or some slight additional preparation beyond the caries $86 \%(321 / 372)$

- Treatment 2: Non-conservative $4 \%$ (15/372)

- No treatment 10\% (36/372).

The material/treatments suggested are shown in Table 2. Among the comments made were: "would wash the cavity with sodium hypochlorite, extraction indicated, depends whether the child has pain, pulpotomy, pulp cap indicated, and, diet advice and dressing needed'.

Table 2 Materials/treatments suggested (331 responses) for cavity in Figure $1 b$

\begin{tabular}{lcc}
\hline Treatment & No. of responses & Percentage \\
\hline Stainless steel crown & 14 & $4 \%$ \\
Cavity made self cleansing & 10 & $3 \%$ \\
Restore with amalgam & 53 & $16 \%$ \\
Restore with glass-ionomer & 153 & $46 \%$ \\
Restore with compomer & 41 & $12 \%$ \\
Restore with amalgam/g.ionomer & 25 & $8 \%$ \\
Restore with g.ionomer/compomer & 9 & $3 \%$ \\
Other & 26 & $8 \%$
\end{tabular}

When asked how they would remove the caries, 7\% (24/377) of respondents indicated that they would use only an excavator, 50\% ( $\mathrm{n}=167)$ would use a drill, 42\% ( $\mathrm{n}=141)$ would use an excavator and drill, none would use a chemical solution such as Carisolv (Medi Team, S-433 63, Savedalen, Sweden), although 1\% (n=5) would use a chemical solution with a drill or excavator. Fifty-two per cent of respondents (178/341) considered that they would use local anaesthesia for their proposed treatment, while 5\% (18/337) would use relative analgesia. With regard to the respondents' expectation for success of their proposed treatment, 22\% (75/343) considered that the prognosis would be excellent, 66\% $(n=228)$ fair and $11 \%(\mathrm{n}=40)$ poor. Ninety-eight per cent of respondents (332/339) would use cotton rolls for isolation, while $1 \%(n=3)$ would use rubber dam.

\section{Statistical analysis}

There were no significant differences in response from dentists in Scotland or England and therefore the data were merged. Response rates were also similar.

There was no evidence of an association between the respondents' awareness of ART as a technique and whether they would use glass-ionomer to restore cavity 1 or cavity 2 ( $p=0.786$ and 0.586 respectively), nor was there any association between whether the respondent worked in a fluoridated area and which material was used to restore cavity $1(p=0.465)$. There was no evidence to suggest a difference in prescribing between dentists in a group or single-handed practice in terms of their awareness of ART $(p=0.409)$, nor was there a difference between dentists working in a fluoridated/non-fluoridated area $(\mathrm{p}=0.236)$.

There was no evidence of an association between years since graduation and whether amalgam was suggested as the material for restoring either cavity 1 or cavity $2(\mathrm{p}=0.377$ and 0.799$)$, nor was there an association between respondents' gender and their use of relative analgesia for either cavity $(p=0.576$ and 0.564). 


\section{Other comments}

A large number of respondents added comments in the section designed for this at the end of the questionnaire. Frequently recurring themes were:

Very poor remuneration for caries management in children by the National Health Service (NHS)

Not cost effective to do a good filling in a primary tooth

Greatly depends on the cooperation and tolerance of the child

Try never to fall out with a child

Avoid GA extractions at all cost

Every child deserves individual attention, so general principles do not apply

Moisture control difficult in a seven-year-old

Minimal intervention and avoidance of LA keeps patients cooperative

Prefer to use stainless steel crowns if marginal ridge is affected Prevention and diet must be discussed.

\section{DISCUSSION}

The ART technique was pioneered in the mid-1980s in Tanzania and further developed in a community field trial in Thailand in 1991 and in another community field trial in Zimbabwe in 1993. ${ }^{14,15}$ The technique has been described by Frencken and coworkers in a World Health Organisation booklet, ${ }^{9}$ who said the two main principles of ART were removing carious tooth tissues using only hand instruments and restoring the cavity with a material that sticks to the tooth.

The reasons for using hand instruments rather than electric handpieces are that it makes restorative care accessible to all populations. It conserves tooth tissue and reduces the need for local anaesthesia. Additionally, infection control is simplified because hand instruments can be readily cleaned and sterilised and hand instruments cost less compared with handpieces.

The results of this survey indicate that although almost half of the respondents were aware of the ART technique, and although most prepared cavities that could be considered to be minimally invasive (as indicated by the prescription of Treatment 1 - Cavity outline closely following the outline of the carious cavity, or some slight additional preparation beyond the caries for 75\% and 86\% of the cavities in Figs 1 and 2 respectively), few were applying the ART in its true form (ie removal of caries without a drill and without a need for LA) in their clinical practice. The cavities chosen for the illustrations in the study questionnaire were selected because each was considered to be appropriate to ART. Hand excavation alone was proposed by less than 10\% of the respondents, with approximately half suggesting the use of a drill and 40\% using an excavator and drill in combination. Few used chemical means of caries removal, which could have been considered appropriate to cavity $1 \mathrm{~b}$ at least. However, more than half of the respondents used materials associated with an adhesive approach, namely glassionomer and compomer. The use of ART was no more likely in younger dentists, who might have been taught the technique at dental school, or among dentists in a group practice, who, in the past were considered to adopt new ideas more readily than singlehanded practitioners. ${ }^{17}$ This was not so in the present survey.

The response rate to the questionnaire was good, given that it was similar to the mean response rate, of $64 \%$, to a dental questionnaire used in another study. ${ }^{16}$ This indicated an interest in the subject and that the novel approach of asking the respondents to draw a cavity outline on the questionnaire was well accepted. However, no details were available on the non-responders, so it must be considered that the respondents were those who were interested in the questionnaire topic, and the results may therefore represent a best-possible scenario, with the non-responders being less likely to be minimally-interventionist and less likely to be interested in ART.
The respondents appeared to represent a group of practitioners in a stable practising environment, given that the mean number of years that they had been at their current address was 11 years. It could therefore be considered that they would be keen to build good relations with their child patients, ie potential patients of the future.

Few respondents considered pulp therapy despite the readiness at which cavitated primary molar teeth exhibit pulpal inflammation ${ }^{18}$ or the use of stainless steel crowns, despite their superior longevity in treatment of multi-surface cavities. ${ }^{19}$

This study indicated that knowledge of the ART technique, as originally described, was less than fully adopted by the respondents to this questionnaire, despite the fact that almost half the respondents claimed to be aware of ART and there had been worldwide interest in the technique. ${ }^{20}$ There may be several reasons for this: they may have considered that it was only appropriate to the areas for which it was originally considered suitable, namely in un-industrialised countries, rather than in practices in the UK. They may also have considered that using a drill was faster than ART, a factor of importance in view of the many comments relating to the inadequate remuneration for treatment of caries in primary teeth within the NHS.

Examination of the cavity outlines drawn by respondents (Figs 2 a-f) revealed that some were using a cavity preparation that had not embraced minimally-intervention principles and which, at best, was destructive of tooth substance, let alone its adverse effect on the pulp and on the patient's opinion of dentistry. Further education in restorative techniques in children would therefore appear to be indicated, and to educate dentists in the advantages of a minimal intervention approach, such as ART, which often does not require the use of LA. Alternatively, it might be that some dentists who did not adopt an ART approach did not feel that it was appropriate in the cavities illustrated, rather than being unaware of ART.

Some respondents commented on the perceived poor remuneration for treatment of children within the General Dental Services of the NHS in the UK. It could be considered that the ART approach would be helpful here, given that there is often no need for the administration of LA, and, accordingly, time could be saved. Conversely, it has been considered that the ART is more time consuming than the conventional 'drill and fill' approach ${ }^{21}$ This should be balanced against the findings that patients find the ART approach more comfortable and less stressful than conventional cavity preparation, ${ }^{22,23}$ potentially leading to benefits in patient (and parent) co-operation.

Over half the respondents said they would employ a dental therapist for the treatment of child patients in their practice. As this is now legal, and apparently, according to our results, something which is becoming accepted by dentists, there would appear to be an indication for training of increased numbers of therapists than at the present time. This could help to address the large unmet treatment need in children with caries in the primary dentition. In this respect, a recent report has stated that there has been no improvement in dental health in some localities over the past 15 years. ${ }^{24}$ In this respect, there may be an opportunity for the use of ART in non-dental settings such as school visits.

Finally, the questionnaire requested respondents' help with a follow-up research project in which cavity outlines would be mapped in their practices. This request for help was favourably received, with approximately $25 \%$ of respondents offering assistance. The results of the present project, which showed a less than minimal approach to cavity preparation by a substantial proportion of respondents, indicated a need for further research into practitioners' rationale for their chosen cavity designs and influencing factors. 


\section{CONCLUSIONS}

Although just less than half of the respondents in this survey indicated they were aware of Atraumatic Restorative Treatment, few had adopted it in its true form in their treatment of caries. More education of UK general dental practitioners is indicated in minimal intervention techniques and caries management in the treatment of the primary dentition.

The authors acknowledge the financial support of GC Europe NV, Leuven, Belgium for this project, and wish to thank the practitioners who completed and returned the questionnaires. Mr Mike Sharland, Multimedia Services, University of Birmingham School of Dentistry is acknowledged for his help with the illustrations.

1. O'Brien M. Children's dental health in the United Kingdom, 1993. London:Her Majesty's Stationery Office, 1994

2. Cole B O, Welbury R R. The atruamatic restorative treatment (ART) technique: does it have a place in everyday practice? SAfr DentJ 2001; 56:321-326.

3. Levine R S, Pitts N B, Nugent Z J. The fate of 1587 unrestored carious deciduous teeth:a retrospective general dental practice based study from northern England. $\mathrm{Br}$ Dent J 2002: 193: 99-103.

4. Milsom K M, Tickle M, Blinkhorn A S. Dental pain and dental treatment of young children attending the general dental service. Br Dent J 2002; 192: 280-284.

5. Tickle M, Milsom K M, Kearney-Mitchell P, Blinkhorn A S. The fate of carious primary teeth of children who regularly attend the general dental service. Br Dent J 2002; 192: 219-223.

6. McDonald S P, Sheiham A. A clinical comparison of non-traumatic methods of treating caries. Int Dent J 1994; 44: 465-470.

7. Ribeiro C C, Baratieri L N, Perdigao J, Baratieri N M M, Ritter A V. A clinical, radiographic and scanning electron microscopic evaluation of adhesive restorations on carious dentin in primary teeth. Quintessence Int 1999; 30: 591-599.

8. Frencken $J$ R. Report on the execution of the Morogoro rotation in primary oral health care in the academic year 1984-1985. University of Dares Salaam, Division of Dentistry, 1985

9. Frencken J, Phantumvanit P, Pilot $T$, Songpaisan $Y$, van Amerongen E. Manual for Atraumatic Restorative treatment. 1997, WHO Collaborating Centre for Oral Health Services research, Groningen.
10. Ewoldson N, Covey U. and Lavin M. The physical and adhesive properties of dental cements used for atraumatic restorative treatment. Spec Care Dent 1997; 17: 19-24.

11. Mjor I A, Gordan W A. Review of atraumatic restorative treatment (ART). Int Dent $J$ 1999; 49: 127-131.

12. Lo E C, Luo Y, Clinical investigation of two glass ionomer restoratives used with the atraumatic restorative treatment approach in China: two years results. Caries Res 2001; 35: 458-463.

13. Dillman D A. Mail and telephone surveys; The Total Design method. New York: John Wiley and sons, 1977.

14. Phantumvanit $P$, Songpaisan $Y$, Pilot $T$, Frencken J E. Atruamatic Restorative Treatment (ART): a three-year community field trial in Thailand - survival of one surface restorations in the permanent dentition. J Public Health Dent 1996; 56: 141-145.

15. Frencken J E, Makoni F, Sitholen D. ART restorations and glass ionomer sealants in Zimbabwe:survival after 3 years. Community Dent Oral Epidemiol 1998; 26: 372-381.

16. Tan R T, Burke FJ T. Response rates to questionnaires mailed to dentists. A review of 77 publications. Int Dent J 1997; 47: 349-354.

17. Sarll D W, Holloway P J. Factors influencing innovation in general dental practice. $B r$ Dent J 1982; 153: 264-266.

18. Duggal M S, Nooh A, High A. The relationship between extent of caries involvement of the marginal ridge and pulp inflammation of primary teeth. J Dent Res 1999 78: 298

19. Fayle S. Stainless steel preformed crowns for primary molars. Int J Peadiatric Den 1999; 9: 31-314.

20. Frencken J E, Holmgren C J.The Atraumatic Restorative Treatment (ART) for tooth decay. A Global initiative 1998-2000. Final report and recommendations. World Health Organisation, 2002

21. Cole B O I, Welbury R R. The Atraumatic Restorative Treatment (ART) Technique: does it have a place in everyday practice? Dent Update 2000; 27: 118-123.

22. Van Amerongen W E, Rahimtoola S. Is ART really atraumatic? Community Dent Oral Epidemiol 1999; 27: 431-435.

23. Schriks M C, van Amerongen W E. Atraumatic aspects of ART: psychological and physiological aspects of treatment with and without rotary instruments. Community Dent Oral Epidemiol 2003; 31: 15-20.

24. Audit Commission. Dentistry. Primary dental care services in England and Wales. Exhibit 6, p 24. London: The Audit Commission, 2002. 